\title{
OBSERVATIONS ON SOME VARIATIONS OF THE MALES IN CLINIDIUM.
}

BY FREDERICK BLANCHARD, LOVELI, MASS.

In the Transactions of the American Ent. Soc. v. p. I62, Dr. LeConte discusses at some length the Rhysodida of the United States. A recent examination of a small series of Clinidium showed, on comparison with the notes and descriptions in the above mentioned paper, quite considerable differences in the $\delta$ characters. There are before me four males and nine females. Of these, only one, a $q$ without locality, has the thorax oblong as required by the definition of sculptile given by LeConte. The others have the thorax distinctly narrower anteriorly as is said of calcaratum. One of from D.C. agrees in its sexual characters with the description of sculptile; the anterior tibiæ, however, are much more strongly angulate than is indicated by the figure given. For the sake of comparison the following copy is given of the description of the $\delta$ of sculptile; - "Front thighs distinctly toothed; front tibiæ rather suddenly dilated on the inner side, above the oblique groove, then sinuate; middle and hind tibiæ subsinuate on the inner side, produced inwards at tip into a sharp process. Prosternum with a broad stripe of velvety surface; ventral segments with spots of similar pubescence."

In calcaratum $\delta$, the "Front thighs are not toothed; front tibiæ very feebly dilated on the inner side; middle and hind tibiæ with a large pointed apical process on the inner side, one half the length of the tibiæ; under surface without velvety spots.

A second $\delta$ from $N$. C. is like the first mentioned, but differs in having the hind thighs distinctly toothed inside, just before the apex, and in the prosternum being quite smooth at the middle, without any trace of velvety pubescence. The hind tibiæ are more distinctly sinuate.

In two other males also from N. C., the front thighs have a small tooth; the front tibiæ are rather suddenly narrowed at base and not at all angulate; the middle and hind tibiæ with apical inflexed process, on the posterior ones very strong, apparently quite as well developed as is said of calcaratum; hind thighs as usual, merely sinuate before the apex ; prosternum smooth, abdomen with velvety pubescence on the first four segments.

A majority of the females seen have the last ventral strongly protuberant at middle, and transversely impressed behind. Others are intermediate between these and those having the same segment merely feebly convex. In all, the front thighs are not toothed, the middle and hind tibiæ simple and the prosternum and abdomen without velvety spots at middle. 
To exhibit it a glance the differences in the males the following table is added : Anterior ventral segments pubescent at middle, front thighs toothed.

Front tibiæ angulate.

Hind thighs not toothed, prosternum velvety pubescent at middle.

A. sculptile.

Hind thighs toothed, prosternum smooth.

Front tibiæ sinuate, not at all angulate, prosternum smooth, hind tibiæ with stronger apical process.

C.

Ventral surface without velvety pubescence along the middle, front thighs not toothed, front tibiæ not angulate, apical processes of middle and hind tibiæ very long.

D. calcaratum.

C. sculptile Newm. is not rare in the
Atlantic States. Colcaratum Lec is from Or. and V.I.

Were the above described secondary $\delta$ characters in $\mathrm{A}, \mathrm{B}$, and $\mathrm{C}$, accompanied by any constant differences in form or sculpture, three very distinct species would seem to be indicated; but there does not appear to be the slightest clew to show which females belong with any of the males, and it is perhaps not impossible that a series of specimens may prove that the $q$ of $D$, is not easily distinguishable from the eastern forms.

In conclusion it is suggested that those who are located within the faunal limits of Clinidium examine their material for the purpose of learning if all the variations mentioned, or any others not yet noted, occur in one locality. In the vicinity of Lowell the family does not appear to be represented.

\section{SOME NEW COMPARISONS OF PIERIS OLERACEA WITH P. NAPI.}

BY SAMUEL HUBBARD SCUDDER, CAMBRIDGE, MASS.

As Pieris oleracea of North America has been regarded as identical with $P$. napi of Europe by some who have studied only the markings of the wings, I have thought a comparison based on the early stages would be desirable; this I am now able to make by the kindness of Mr. J. Jenner Weir of England, who has kindly sent me a number of specimens of blown larvae and living chrysalids of the latter. Other caterpillars from the continent have been ofservice.

The mature caterpillar of $P$. oleracea differs from that of $P$. napi of Europe in the more uniform pile with which the body is clothed, and by the apparent absence of those comparatively large conical wartlets, ten or twelve times larger than the smaller ones, which form so conspicuous a feature in both $P$. napi 

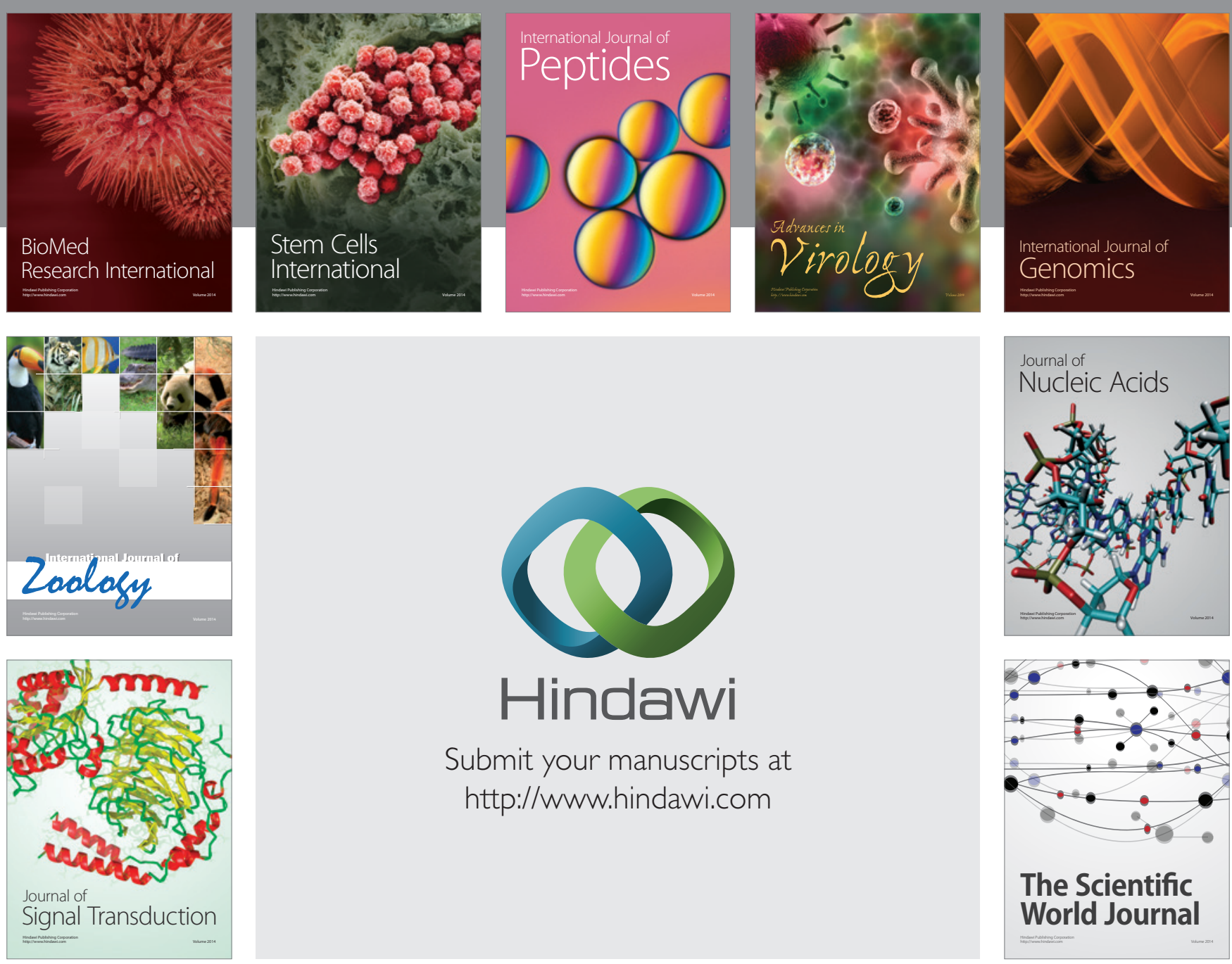

Submit your manuscripts at

http://www.hindawi.com
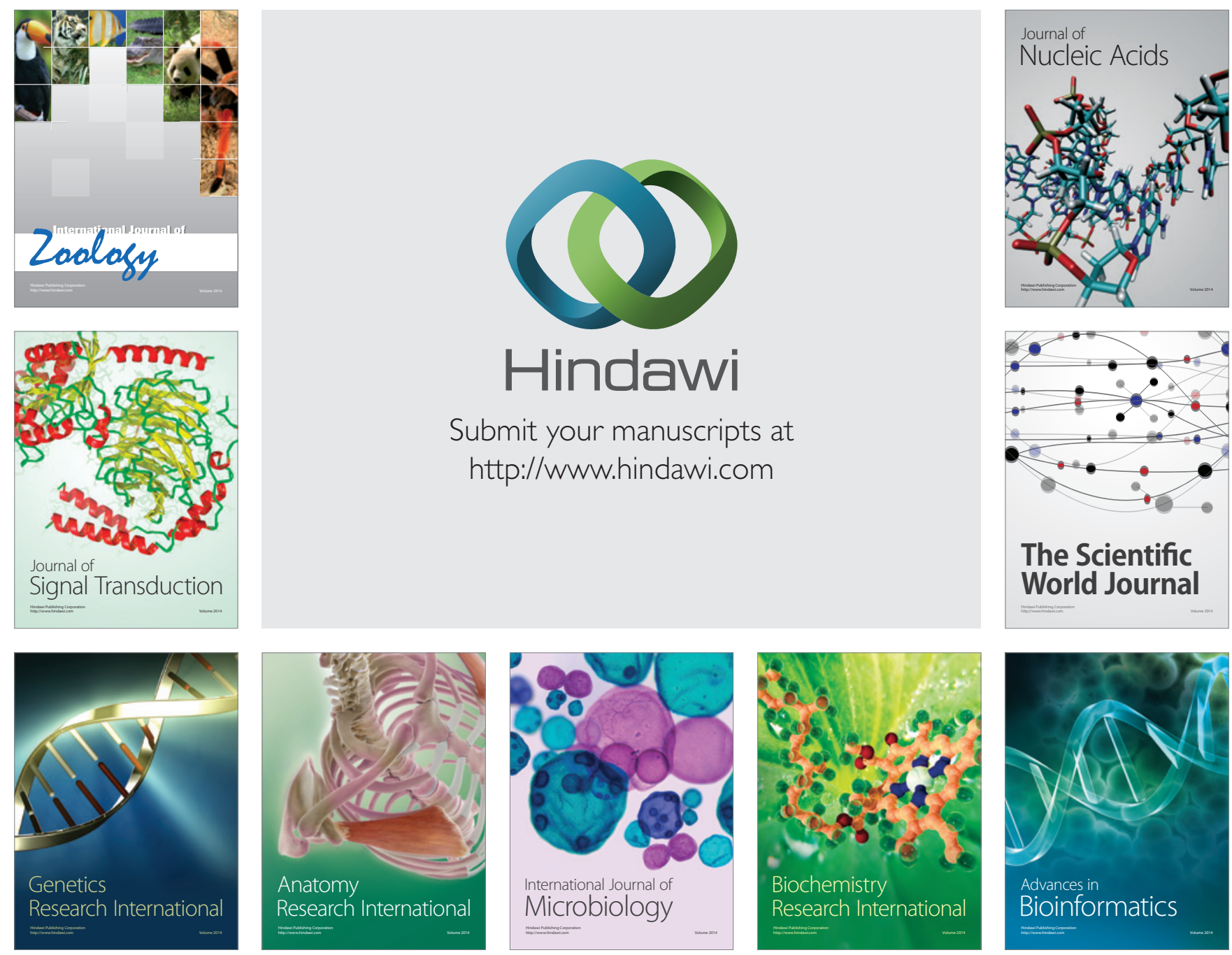

The Scientific World Journal
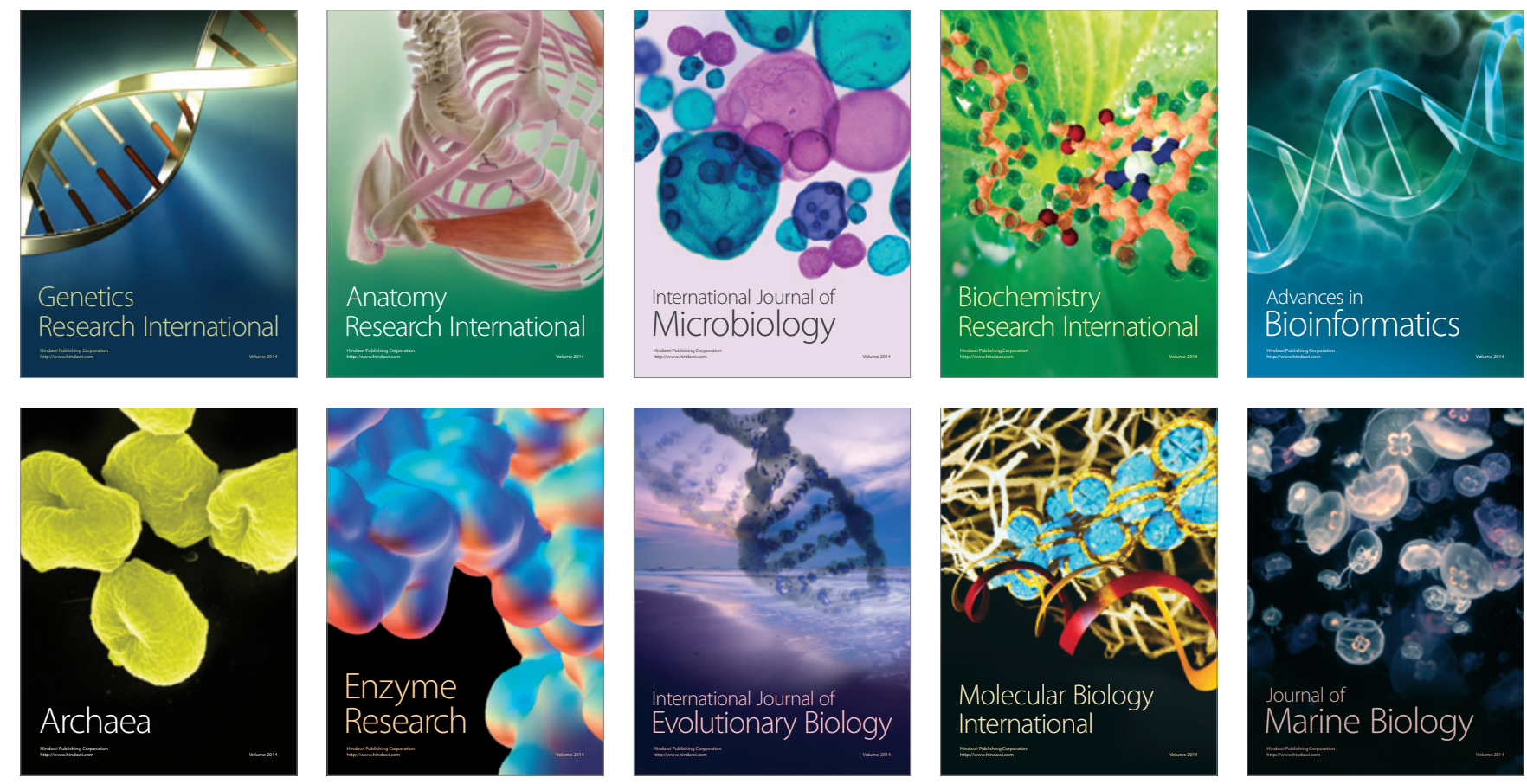